\title{
EXTENDED PAPER
}

Our research's breadth lives on convenience samples A case study of the online respondent pool "SoSci Panel"

Teilnehmerpools im Internet als Forschungsinstrument

Eine Fallstudie zum „SoSci Panel“

Dominik J. Leiner 
Dominik J. Leiner, Institut für Kommunikationswissenschaft und Medienforschung, Ludwig-Maximilians-Universität München, Oettingenstr. 67, 80538 München; Kontakt: leiner(at)ifkw.Imu.de 


\title{
EXTENDED PAPER
}

\section{Our research's breadth lives on convenience samples A case study of the online respondent pool "SoSci Panel"

\author{
Teilnehmerpools im Internet als Forschungsinstrument \\ Eine Fallstudie zum „SoSci Panel“
}

\author{
Dominik J. Leiner
}

\begin{abstract}
Convenience samples have been a substantial driver of empirical social research for decades. Undergraduate students are still the researchers' favorite subjects, but the importance of respondents recruited on the Internet is on the rise. This paper deals with the fuzzy concept of convenience samples, outlining their reasonable uses and limitations. To bolster the theoretical discussion on convenience samples with empirical evidence, findings from the non-commercial SoSci Panel, a large-scale volunteer respondent pool, are presented. Convenience pools allow for larger samples than traditional convenience samples, more heterogeneity, and better long-term availability of respondents. This paper discusses conditions of setting up a respondent pool and methodological and practical implications, such as software, tasks, respondent activity and panel loyalty.
\end{abstract}

Keywords: Access panels, convenience samples, non-probability samples, data quality, survey research, Internet surveys

Zusammenfassung: Convenience Samples sind eine tragende Säule der empirischen Sozialwissenschaften. Neben studentischen „Stichproben“ gewinnt die Rekrutierung freiwilliger Teilnehmer über das Internet an Bedeutung. Dieser Beitrag nimmt sich dem vagen Konzept Convenience Sample an und diskutiert legitime Anwendungsbereiche von Verfügbarkeitsstichproben und deren Grenzen. Zur empirischen Illustration der theoretischen Ausführungen dienen Daten aus dem SoSci Panel - einem großen, nicht-kommerziellen Teilnehmerpool für wissenschaftliche Befragungen. Derartige Pools erlauben vergleichsweise große, heterogene Stichproben mit replizierbarer Struktur, die auch für Längsschnittstudien eingesetzt werden können. Neben den Einsatzbereichen solcher Pools beleuchtet der Beitrag insbesondere praktische Aspekte, wie Software, Wartung und die Loyalität der Teilnehmer.

Schlagwörter: Convenience Sample, Verfügbarkeitsstichproben, Panels, Teilnehmerpools, Datenqualität, Befragungen, Onlinebefragungen

\section{Introduction}

When it comes to the generalization of empirical research, the gold standard is a probability-based random sample. Claims for being representative of the relevant population are also made by quota samples from access panels. Such quota samples enjoy widespread use due to decreasing response quotes in, and the substan- 
tial costs of viable random samples. The overwhelming bulk of academic social research, however, is based on convenience samples. The Journal of Communication, for example, published 44 articles on survey/questionnaire research in 2012 (Vol. 62). Of these 44 studies, 34 make use of convenience samples ${ }^{1}$. Using convenience samples is neither new (Courtright, 1996; Ferber, 1977) nor is it specific to the journal singled out above. Literature reviews on social research issues regularly find the majority of studies based on convenience samples (e.g., Houde, 2002; Potter, Cooper, \& Dupagne, 1993, p. 330; Ryan, Wortley, Easton, Pederson, \& Greenwood, 2001; Sell \& Petrulio, 1996; Sherry, Jefferds, \& GrummerStrawn, 2007; Sparbel \& Anderson, 2000).

This paper discusses legitimate applications of convenience samples, and the option of pooling respondents from many convenience samples in a respondent pool. The term "convenience pool" is used to distinguish such a respondent pool from more elaborate access panels. Ideally, a convenience pool provides a sufficiently large number of highly motivated respondents from different backgrounds, available on demand and throughout multiple survey waves to allow for longitudinal research design. Compared to a traditional convenience sample, the relative continuity of a convenience pool allows exploration of the pool's structures, rendering more knowledge and transparency about the sample under research. To shed light on the concept of convenience sampling in general and convenience pools in specific, this paper will address three questions. Reasoning on these questions is based on data and experiences from the SoSci Panel, a convenience pool founded in 2009, publicly available for non-commercial research since 2011, and providing 100000 panelists in 2016.

\section{Q1: Under which circumstances may we apply convenience samples? \\ Q2: How biased are results collected in the SoSci Panel? \\ Q3: What are the differences between a convenience pool and student samples? \\ Q4: What are the basic conditions of running a convenience pool?}

As a preliminary remark, convenience pools are not an option for commercial access panels, often employed in market research. Their uses are fundamentally different. A convenience pool provides large numbers of respondents who are motivated to do interesting questionnaires - convenience samples that do not claim being representative in any regards. Well-tended commercial panels provide quota samples with a specific demographic structure and/or peculiar samples, e.g. consumers, voters, early adopters, or decision-makers (Göritz \& Moser, 2000; Martinez-Ebers, 1997; Potthoff, Heinemann, \& Güther, 2004).

1 Content analysis by the author: 60 articles overall, 56 of them presenting empirical research classified as survey/questionnaire (44), content analysis (10), Internet metrics (1), and a case study (1). Encoded categories: Age of data, empirical study (yes/no), type of data-collection (see above) and for surveys on people - sample description, convenience sample (yes/no), survey mode, sample size, percentage of female respondents. 


\section{Convenience sampling}

A common definition of convenience sampling is researching those elements of the population that are easily available to the researcher (Saumure \& Given, 2008). The term convenience sample describes neither a systematic sampling method nor a specific sample structure. It rather is a label put on some weakly defined set of respondents. Consequently, there is little literature on convenience samples or how to make the best use of them (e.g., Farrokhi \& Mahmoudi-Hamidabad, 2012; Meltzer, Naab, \& Daschmann, 2012). The term "non-probability sample" is more accurate, but includes a range of sophisticated systematic sampling methods as well. By and large, the term convenience sample describes the opposite of the gold standard, which is a probability based random sample (probability sample) with 100 percent return rate. A probability sample, statistically, provides the best chances that the sample will be representative of the population in all regards - at least regarding the individuals' attributes, not network or group structures. From a statistical point of view, a probability sample's most important advantage is that probabilities of the sampling error are known. In a convenience sample, on the contrary, neither biases nor their probabilities are quantified. In fact, the researcher does not know, how well a convenience sample will represent the population regarding the attributes or mechanism under research. What makes convenience samples so unpredictable is their vulnerability to severe hidden biases.

Due to the severe limitations, some methods literature regards convenience sampling as being an inappropriate (non-)method in social research (Fowler, 2006; Marshall, 1996; O’Leary, 2004; Robson, 2011; Schonlau, Fricker, \& Elliott, 2002). A kinder interpretation of this view is that "convenience samples enable researchers to take risks with their research and explore ideas that may appear farfetched" (Meltzer et al., 2012, p. 252) and that a "justifiable use" of convenience samples is exploration (Ferber, 1977, p. 58). A fundamentally different view is that "a costbenefit analysis" may actually suggest the usage of a convenience sample (Lang, 1996). As a matter of fact, an important body of social science is based on convenience samples (Dooley \& Lindner, 2003; Lunsford \& Lunsford, 1995) and, although convenience samples suffer lots of shortcomings, they have proven sufficient to test psychological theories throughout various topics (e.g., Asch, 1963; Festinger \& Carlsmith, 1959; McCombs \& Shaw, 1972; Milgram, 1963; Shock et al., 1984). So, under what conditions - except for insufficient budget - shall research choose a convenience sample? In literature, we find the following reasoning and circumstances for convenience samples.

Experiments. The subjects from a convenience sample may randomly be assigned to experimental conditions (Meltzer et al., 2012; Newman \& McNeil, 1998; Nock \& Guterbock, 2010). Inference statistics to test group differences are fully applicable in this case (Lang, 1996). There is an extensive discussion on this reasoning in Communication Theory (Basil, 1996; Courtright, 1996; Lang, 1996; Potter et al., 1993, 1995; Sparks, 1995a, 1995b), yet, the most pointed conclusion of the discussion was written earlier by Mook (1983, p. 380): "We are not making generalizations, but testing them." Reasoning is that there is a fundamental difference between surveys and experiments (Berkowitz \& Donnerstein, 1982). 
The intention behind a survey is to observe a sample and generalize the findings. The intention of an experiment is to test a hypothesis against reality, not to describe reality ${ }^{2}$ (Meltzer et al., 2012, p. 252): Can theory predict reality in a specific setting? Any further generalization of the findings, then, is logical inference, not statistical inference (Lang, 1996). This reasoning emphasizes the importance of replication studies that shall attempt falsification of the same hypothesis against other samples.

Uniform processes. When a physicist or chemist conducts an experiment, there is no need to randomly choose the electrons and protons. Given specific conditions, one electron is representative of every other electron all over the world. Similar reductionism is well known from pharmacy, when drugs are tested on animals. This natural scientific perspective is found in psychology, as well: When using convenience samples, researchers sometimes argue that the processes under research are the same regardless of the sample (Basil, 1996; Ferber, 1977; Sim \& Wright, 2000, p. 120). The mental process of classical conditioning, for example, was discovered by observing dogs (Pavlov, 1927). Although not principally wrong, this reasoning is limited to very fundamental processes, based rather on biology than on cognition. Bischof (2009, pp. 249-270) argues that the specific conditions (structure), while meaningless in physics, are elementary in psychology. When researching cognitive processes more complex than conditioning, a broad range of situational factors may be crucial for the outcomes - cultural differences, for example (Henrich, Heine, \& Norenzayan, 2010) - and it is likely that the processes under research are non-uniform.

Controlling biases. If a systematic method is employed to recruit a non-probability sample, biases may be estimated under some circumstances (Tufekci \& Wilson, 2012; van Meter, 1990) or logical reasoning may suggest that the bias is small (Gravetter \& Forzano, 2009, p. 141; Marsden \& Wright, 2010, p. 822). If the sample was not recruited systematically, the researcher may still be able to estimate the bias by comparing the convenience sample to the population, regarding attributes that are likely linked to the process under research (e.g., political views, Internet literacy, health, or personality). Such estimates, however, are disproportionally vulnerable to measurement artifacts and require substantial knowledge about related processes.

Weighting procedures. In the same vein, researchers may consider applying a weighting procedure to reduce biases found in the convenience sample. Wang, Rothschild, Goel, and Gelman (2015) prove that data from a very large convenience sample (more than 300000 respondents) can accurately predict the US presidential election outcome - a single margin. Other literature is rather discouraging, especially if results are more complex. Schonlau, van Soest, Kapteyn, and Couper (2009) as well as Rookey, Hanway, and Dillman (2008) apply weighting and matching procedures on data retrieved from a probability-based Internet sample (recruited offline). These procedures reduce biases compared to an offline probability sample; yet, even in this formidable Internet sample, a considerable

2 Note, that testing hypotheses is not limited to experimental designs, but may also include quasiexperimental designs (correlation studies). The aspect of testing hypotheses is crucial in that case. 
amount of bias remains. By weighting data collected in an access panel, Loosveldt and Sonck (2008) only gain minor improvements in the results. Varedian and Forsman (2003) apply different weighting procedures on data from a volunteer panel and find none that significantly reduces biases, compared to a telephone survey. In conclusion, it is very unlikely that results from a convenience sample will benefit from weighting procedures.

Negligible biases. Finally, one may hope that a large sample collected in a Webbased survey approaches the population's structure merely by the substantial number of cases. This hope is built on a confusion of the random sampling error, which depends on sample size, and systematic biases, caused by the sampling procedure. As a matter of fact, "there is no reason to believe that large convenience samples are less biased than those from a smaller convenience sample." (Whitehead, 2007, p. 798; similarly Hargittai, 2015)

Real-world restrictions. Sometimes, a convenience sample is the best possible sample to research a phenomenon. Ethical restrictions may demand a volunteer sample (e.g., the Stanford Prison experiment, Zimbardo, 2007), the research focus is a "hidden population" like homeless people (Salganik \& Heckathorn, 2004) or a society in a crisis situation (e.g., Tufekci \& Wilson, 2012), or the research is not on individuals, but on groups or networks (e.g., Weimann, 1982). The alternative to a non-probability sample would be gathering no data at all. In such a case, all that research can do is to "provide a clear description of how the sample was obtained" (Gravetter \& Forzano, 2009, p. 142), so readers can make their own judgments on the sample and likely biases.

In response to question $1(\mathrm{Q} 1)$, experimental designs are the only widely accepted application of convenience samples. The same reasoning applies to quasi experimental designs (correlation studies). The rationale is, that a hypothesis is tested against a (conveniently available) part of reality - if generalizations are drawn (including effect strengths), these are logical, not statistical inferences. Other reasoning for convenience samples, namely that the cognitive processes under research are equally valid for each human, or that the sample is representative regarding the attributes under research, is unlikely but not necessarily wrong. It is up to the researcher to substantiate such assumptions.

If a researcher decides to use a convenience sample, there may be some advantages in recruiting this sample from a convenience pool. This paper presents the case of such a convenience pool, the German SoSci Panel. Based on empirical data, the theoretical limitations that were discussed above (Q1) will be quantified for the practical case of the SoSci Panel (Q2). Based on experiences from the SoSci Panel, advantages and drawbacks of a convenience pool are discussed (Q3), as well as practical considerations of running such a pool (Q4).

\section{The SoSci Panel}

The SoSci Panel was founded as a non-commercial project in 2009 by SoSci Survey. Questionnaires can be submitted free of charge. Their compliance with the pool's standards (see below) is ensured by a peer review process, which often results in major improvements to the instrument before data is collected. As the 
SoSci Panel is currently available only in the German language, questionnaires require a German version to be allowed for submission.

SoSci Survey is a company providing software to create online questionnaires. The software is especially popular in Germany, where the company is located, but also available in English. The majority of this platform's users are university students and $\mathrm{PhD}$ candidates, who conduct online surveys with convenience samples. Users of SoSci Survey can choose whether to show an invitation to the SoSci Panel subsequent to their questionnaire or not ${ }^{3}$. This invitation simply asks respondents to leave their email address if they are interested in doing further online questionnaires. About 3800 respondents leave their email address every month, and 2500 of them subsequently confirm their participation in the SoSci Panel (data from 08/2015 to 07/2016). To avoid non-active panelists, email addresses are removed when their owners do not respond once in the recent eight surveys. In 2016, the SoSci Panel comprises nearly 100000 email addresses (fluctuating due to the removal procedure). Obviously, email communication (that is virtually free of charge) and online questionnaires were necessary preconditions for a non-budget convenience pool like the SoSci Panel.

In compliance with German law, registration for the pool requires a double opt-in procedure: After leaving their email address, respondents receive a confirmation email containing a hyperlink to confirm pool membership. The SoSci Panel makes use of this registration step to ask the new panelist for demographic master data (age, gender, formal education, etc.). Disclosure of these data is voluntary ${ }^{4}$, which accounts for privacy concerns. Keeping the barrier low is especially important, as the panelists do not receive compensations for participating the pool or doing questionnaires. Further concessions for the pool members are (1) that their data will not be passed to third parties, (2) they will not receive invitations to commercial research projects from the SoSci Panel, (3) the survey load is limited to four invitations per year, and (4) questionnaires are relevant for the majority of panelists, diversified regarding their content and form (this excludes scale development studies with 200 similar items), well-tested, easy to understand, polite, and no longer than 25 minutes.

\section{Result biases in research practice}

The discussion on convenience samples (above) clearly rules out statistical inferences. Yet, logical inferences are quite common - namely, the premise that a hypothesis supported in a convenience sample will as well find support in another context or in the general population. A common assumption is that descriptive statistics (margins, means, etc.) are heavily biased, while interrelations (group differences and correlations) are similar in the convenience sample and the popula-

3 The invitation form is shown by default in non-commercial survey projects on SoSci Survey and can be disabled. From $02 / 2015$ to $07 / 2016$, two out of five $(42 \%)$ respective surveys $(N=4.203)$ showed the invitation form.

4 Most panelists $(76 \%)$ provide information on all seven details (year of birth, gender, formal education, occupation, having children, country, and postal code), whereas one eighth $(11 \%)$ does not provide any information at all $(N=97870$ panelists in 08/2015). 
tion. Such an assumption is based on the questionable postulate of uniform processes. Empirical evidence on the biases of margins, effect strengths, and test results is sparse. Data collected in the SoSci Panel provides the opportunity to give researchers some quantitative directions.

Between 2011 and 2013 there have been four research projects that collected data in the SoSci Panel (SP) and in another context (OC) at the same time, using the same questionnaire. The researchers agreed to conduct additional analyzes on their data, regarding differences between the two samples. The other samples comprise one snowball quota sample, secondary public data, and two nationally representative probability samples. Note, that the other data was not collected online but face-to-face and by telephone in three of the research projects. Effects of the interview mode may therefore increase the observed biases.

(1) A study by Volkenandt (2012) allows direct comparisons between two nonprobability samples. One sample was recruited from the SoSci Panel $(n=345)$ the other is a quota-stratified sample $(n=223)$ based on a binding snowball procedure (Volkenandt, 2012): The researcher asked 48 acquaintances, each, to persuade five other people to complete the questionnaire. To ensure demographic variation, the acquaintances were given quota scheduled for age and formal education. Needless to state that the binding snowball exceeded the SoSci Panel by far, regarding response rate $(94 \%$ v. $17 \%$ completed questionnaires), completion rate $(0 \%$ v. $10 \%$ drop-outs), and demographic heterogeneity. Regarding data quality, no systematic differences were found between the samples (Appendix). To test for biases in descriptive findings, a question on the personal importance of news sections (politics, sports, local news, soft news) was analyzed. Although there are significant differences regarding the importance of politics $\left(t=-2.93, p<.01, M_{\mathrm{SP}}=5.3\right.$, $\left.M_{\mathrm{OC}}=5.0\right)$ and sports $\left(t=4.1, p<.001, M_{\mathrm{SP}}=2.3, M_{\mathrm{OC}}=3.0\right)$, the absolute differences turned out to be smaller than the demographic differences would have suggested. The study's dependent variable was a subjective feeling of being wellinformed (7-point one-item measure, Volkenandt, 2012, p. 106). Gender and topic interest, which explained this variable to a very different degree (one-item measures, each), were tested for sample biases. While topic interest showed similar effects on the feeling of being well-informed in both samples (politics: $r_{\mathrm{SP}}=.41^{* * *}$, $r_{\mathrm{OC}}=.40^{* * *}$, sports: $r_{\mathrm{SP}}=.19^{* * *}, r_{\mathrm{OC}}=.14^{*}$, soft news: $r_{\mathrm{SP}}=-.09$ n.s., $r_{\mathrm{OC}}=.00$ n.s.), the researcher would have drawn different findings on the effect of gender $\left(\eta_{\mathrm{SP}}=.24 * * *, \eta_{\mathrm{OC}}=.11\right.$ n.s., SP: $M_{\mathrm{F}}=3.9, M_{\mathrm{M}}=4.5$, OC: $\left.M_{\mathrm{F}}=4.1, M_{\mathrm{M}}=4.3\right)$.

(2) A study by Leiner (2016) on the stability of public opinion includes a question on voting intention for the German national government election. 
Table 1: Voting intention reported by panelists and nationally representative samples

\begin{tabular}{|c|c|c|c|c|c|}
\hline & \multicolumn{2}{|c|}{ Voting intention } & \multicolumn{3}{|c|}{ Time series of voting intention } \\
\hline & $\begin{array}{l}\text { SoSci } \\
\text { Panel } \\
\end{array}$ & $\begin{array}{c}\text { Infratest } \\
\text { dimap }\end{array}$ & $\begin{array}{c}\text { Cross- } \\
\text { correlation } \\
\text { (Pearson's r) }\end{array}$ & $\begin{array}{l}\text { Standard de } \\
\text { SoSci } \\
\text { Panel } \\
\end{array}$ & $\begin{array}{c}\text { iation (SD) } \\
\text { Infratest } \\
\text { dimap } \\
\end{array}$ \\
\hline $\mathrm{CDU} / \mathrm{CSU}$ & $17.8 \%$ & $34.4 \%$ & -.14 & $\pm 1.0 \%$ & $\pm 1.5 \%$ \\
\hline SPD & $20.0 \%$ & $29.0 \%$ & -.33 & $\pm 1.4 \%$ & $\pm 1.4 \%$ \\
\hline B90/ Grüne & $34.2 \%$ & $16.3 \%$ & +.57 & $\pm 2.7 \%$ & $\pm 3.2 \%$ \\
\hline Die Linke & $7.5 \%$ & $6.7 \%$ & -.58 & $\pm 1.0 \%$ & $\pm 0.7 \%$ \\
\hline FDP & $3.4 \%$ & $3.7 \%$ & +.77 & $\pm 0.8 \%$ & $\pm 0.9 \%$ \\
\hline Other parties & $17.1 \%$ & $9.9 \%$ & +.71 & $\pm 2.8 \%$ & $\pm 2.9 \%$ \\
\hline Sample size $(\mathrm{N})$ & 8182 & 32584 & 13 months & 13 months & 13 months \\
\hline
\end{tabular}

Notes: The left part shows the average voting intention measured from $07 / 2011$ to $08 / 2012$. There are 13 monthly measures behind each of the values. The correlation of these time series is given in the middle column. Right is the standard deviation of the time series $(S D, N=13)$, i.e., a measure how unstable the party share is over time.

Different panelists were asked this question at different times throughout one year (longitudinal panel design, 07/2011-08/2012). Nationally representative data on the same question, based on telephone interviews, is available from Infratest dimap (2012) and reveals the measured from the SoSci Panel as being strongly biased (Table 1, left). During the 13 months of observation, little change occurred in the aggregate party shares - mostly within random sampling error of the SoSci Panel sample ${ }^{5}$ (average $n=629$ ). Consequently, only random correlations are observed between time series $(N=13$ months, Table 1 , middle). The study's focus, however, is not on specific changes, but on the variance of public opinion. In stark contrast to the other aspects, the bias regarding this variance is small: Time series' standard deviations (Table 1, right) correlate with $r=.92^{6}$ when comparing both samples.

5 Respondents were randomly assigned to the 13 months. On average, 629 respondents completed the questionnaire each month.

$6 N=6$ parties/other, Pearson's product-moment correlation, corrected for theoretical SD due to different selection probability (uncorrected $r=.95$ ). 
Table 2: Voting intention and expectations about the election result

\begin{tabular}{|c|c|c|c|c|}
\hline & \multicolumn{2}{|c|}{ Voting intentions } & \multicolumn{2}{|c|}{ Election result expectations } \\
\hline & SoSci Panel & Prop. Sample & SoSci Panel & Prop. Sample \\
\hline $\mathrm{CDU} / \mathrm{CSU}$ & $24 \%$ & $44 \%$ & $\begin{array}{c}37 \% \\
{[0.363 \mid 0.370]}\end{array}$ & $\begin{array}{c}37 \% \\
{[0.361 \mid 0.383]}\end{array}$ \\
\hline SPD & $20 \%$ & $24 \%$ & $\begin{array}{c}27 \% \\
{[0.267 \mid 0.273]}\end{array}$ & $\begin{array}{c}29 \% \\
{[0.276 \mid 0.296]}\end{array}$ \\
\hline B90/Grüne & $26 \%$ & $13 \%$ & $\begin{array}{c}13 \% \\
{[0.125 \mid 0.129]}\end{array}$ & $\begin{array}{c}11 \% \\
{[0.101 \mid 0.114]}\end{array}$ \\
\hline Die Linke & $10 \%$ & $8 \%$ & $\begin{array}{c}7 \% \\
{[0.068 \mid 0.071]}\end{array}$ & $\begin{array}{c}6 \% \\
{[0.051 \mid 0.059]}\end{array}$ \\
\hline FDP & $5 \%$ & $4 \%$ & $\begin{array}{c}6 \% \\
{[0.059 \mid 0.063]}\end{array}$ & $\begin{array}{c}6 \% \\
{[0.054 \mid 0.062]}\end{array}$ \\
\hline AfD & $4 \%$ & $3 \%$ & $\begin{array}{c}3 \% \\
{[0.026 \mid 0.029]}\end{array}$ & $\begin{array}{c}2 \% \\
{[0.014 \mid 0.018]}\end{array}$ \\
\hline Piraten & $7 \%$ & $1 \%$ & $\begin{array}{c}4 \% \\
{[0.034 \mid 0.037]}\end{array}$ & $\begin{array}{c}3 \% \\
{[0.021 \mid 0.028]}\end{array}$ \\
\hline Other parties & $4 \%$ & $2 \%$ & $\begin{array}{c}4 \% \\
{[0.040 \mid 0.046]}\end{array}$ & $\begin{array}{c}2 \% \\
{[0.019 \mid 0.026]}\end{array}$ \\
\hline Sample size $(N)$ & 1144 & 1000 & 1144 & 1000 \\
\hline
\end{tabular}

Notes: Data from 09/2013. The nationally representative telephone sample is probability weighted. Voting intention only includes valid responses, excluding non-voters and indecisive voters.

(3) There is evidence that even extremely biased samples, like a convenience sample, may be useful for forecasting election outcomes (Rothschild \& Wolfers, 2012). Ganser and Riordan (2013) asked respondents from the SoSci Panel and a nationally representative probability-based sample (telephone interviews, probability weighted) for their voting intention and their expectations about the results in the 2013 German national election. Voting intentions 2013 show similar biases like already found in 2011/2012 (Tables 1 and 2), and expectations about the election result are systematically different, as well (Table 2). Political knowledge, tested by three singlechoice questions, is also very different in the SoSci Panel and the telephone sample (questions answered correctly by $M_{\mathrm{SP}}=72.8 \%$ and $M_{\mathrm{OC}}=42.7 \%$ ). To test for effect biases, age and gender differences in voting behavior were analyzed. In both samples, voters of Bündnis 90/Die Grünen were younger $\left(M_{\mathrm{SP}}=35.5 \mathrm{a}, M_{\mathrm{OC}}=45.7 \mathrm{a}\right)$ than $C D U / C S U$ voters $\left(M_{\mathrm{SP}}=36.4 \mathrm{a}, M_{\mathrm{OC}}=53.2 \mathrm{a}\right)$, yet the size of this effect is very different $\left(r_{\mathrm{SP}}=+.03, r_{\mathrm{OC}}=+.19\right)$. $S P D$ voters $\left(M_{\mathrm{SP}}=36.9 \mathrm{a}, M_{\mathrm{OC}}=52.9 \mathrm{a}\right)$ are about the same age as CDU/CSU voters in both samples $\left(r_{\mathrm{SP}}=-.02, r_{\mathrm{OC}}=+.01\right)$. The effect of gender on voting intention is very weak. In the probability sample, it approaches statistical significance $(p<5 \%)$ only for the party $A f D\left(r_{\mathrm{SP}}=-.10, r_{\mathrm{OC}}=-.08\right)$. Based on the sample from the SoSci Panel, one would have found support for this effect for Bündnis 90/Die Grünen $\left(r_{\mathrm{SP}}=+.11, r_{\mathrm{OC}}=+.01\right)$ and three other parties (FDP, Piraten, AfD), i.e., four out of seven parties under research.

(4) Scherr and Reinemann (2013) conducted a nationally representative telephone survey that included a 17-item telephone version (BDI-T) of the well-established Beck Depression Inventory (Beck, Ward, Mendelson, Mock, \& Erbaugh, 
1961). The telephone survey was restricted to a cross-section design, but the question for causality is critical, when researching the relations of media use and mental health. Therefore, data was also collected in the SoSci Panel in a two-wave longitudinal design. The questionnaires used in wave one (SP) and in the telephone survey (OC) were the same. Descriptive statistics about the telephone sample and wave one in the SoSci Panel reveal substantial differences: Given the same cut-off applied to both samples, the percentage of subclinical depressive respondents (BDI-T index above cut-off) is three times higher in the SoSci Panel's sample than in the representative sample (Table 3). Mode differences may account for this difference and put the seemingly fundamental difference into perspective 7 .

\section{Table 3: BDI-T depression measures and correlations observed in the SoSci Panel and in a nationally representative sample}

\begin{tabular}{|c|c|c|c|c|}
\hline & \multicolumn{2}{|c|}{ SoSci Panel } & \multicolumn{2}{|c|}{ Telephone sample } \\
\hline & women & men & women & men \\
\hline \multicolumn{5}{|l|}{ Descriptive statistics } \\
\hline Average BDI-T & 47.1 & 44.0 & 37.4 & 35.4 \\
\hline Subclinical depressives & $28 \%$ & $25 \%$ & $12 \%$ & $9 \%$ \\
\hline \multicolumn{5}{|l|}{ Correlations } \\
\hline BDI-T - Television use & +.01 n.s. & -.05 n.s. & $+.26^{* *}$ & $+.21 * *$ \\
\hline BDI-T - Internet use & +.04 n.s. & $+.11 *$ & -.04 n.s. & +.03 n.s. \\
\hline BDI-T - Self esteem & $-.71 * *$ & $-.69 * *$ & $-.58 * *$ & $-.54 * *$ \\
\hline BDI-T - Suicidal tendency & $+.49 * *$ & $+.46 * *$ & $+.51 * *$ & $+.59 * *$ \\
\hline Sample size $(N)$ & 814 & 528 & 1012 & 990 \\
\hline
\end{tabular}

Notes: Data from 09/2013. The nationally representative telephone sample is probability-weighted.

Analyzes of the effects of media use on depression would also result in completely different findings: Correlations between television use and depression are only found in the telephone sample (note, that this is an effect of the samples' different age $^{8}$ ), while correlations between Internet use and depression are exclusively found in the Internet sample. The mode of a web-based survey, of course, is strongly related to Internet usage. As soon as another effect is tested, which has no obvious relation to the Internet, consistent effects are found in both samples. The correlation between BDI-T and self-esteem (Collani \& Herzberg, 2003) or suicidality (Pöldinger, 1968), for example, showed similar effect sizes in both samples.

Response to question $2(\mathrm{Q} 2)$. The figures from the different studies contribute empirical evidence to the (mostly) theoretical discussion on convenience samples.

7 Donker, van Straten, Marks, and Cuijpers (2010) present evidence that higher cut-offs for depression scales are necessary when applied in a web-based questionnaire. The high anonymity, subjectively granted by the Internet, likely eases disclosure of depressive dispositions (Crippa et al., 2008). Yet, the percentage of subclinical depressive respondents found in the telephone survey is very close to that, other studies found with printed questionnaires, that were completed anonymously, as well (Scherr \& Reinemann, 2013).

8 If analyzing only the respondents aged 29 to 39 years in the telephone sample, the correlation between BDI-T and television vanishes. 
The claim that descriptive findings are very specific for a sample finds strong support in the data: The margins and averages found in a convenience sample - even a heterogeneous one - are in no way indicative of the population. Regarding explanatory findings, we find a mixed picture: On one hand, many effects found in the SoSci Panel are similarly found in a probability sample or in other non-probability samples. Uniform processes, as depicted above, may explain some of these robust correlations. The strong relation between depression and self-esteem (Table 3), for example, found support in a considerable number of studies (Sowislo \& Orth, 2013). On the other hand, there are significant contradictions to the rule: Some effects are found in the convenience sample but not in the population, and vice versa ${ }^{9}$. By and large, these observations support the theoretical rationale: First, statistical inferences based on convenience samples are not allowed at all. Second, the chances are quite small that an effect found in a convenience sample will have the same effect size in the population. And third, there is a good chance, but no guarantee, that effects that find support in a convenience pool will also find support in other samples and/or the population: Logical inferences about effects are not typically wrong, yet they deserve some caution.

\section{Advantages and drawbacks of sampling from a convenience pool}

Student samples have some important advantages for day-to-day research, concerning scheduling, survey load capacity, or incentives, for example. Yet, a complex experimental design may require a larger number of respondents, or a quasiexperimental design may necessitate more heterogeneous respondents. Time may also be a critical factor, for example to collect reactions to an event that likely occurs but cannot be scheduled (e.g., a political scandal). This paper's third question (Q3) seeks to clarify the features of a research design that speak in favor or against recruiting from a convenience pool.

Survey mode. Currently, there is no communication channel cheaper than the Internet for sending personalized messages to thousands of receivers. The opportunity of email allows for convenience pools at low costs and efforts, but limits subsequent communication. Practically, a convenience pool is only an option if the survey mode shall be online. Other survey modes are tied to significant costs, and the (relative small) savings of using a convenience sample instead of more elaborate sampling strategies then will not outweigh the limitations.

Heterogeneity. A typical attribute of traditional convenience samples is their homogeneity: Freshmen from the same faculty are of the same age, have similar income, family status, and even curriculum knowledge. This may, in some aspects, lead to similar views or even similar cognitive processing. Students' friends and family are mostly from the same region and often share a higher socioeconomic status. Sample heterogeneity may be both, a benefit or a drawback. In an experiment, a homogeneous sample reduces within-group variance, and the betweengroup differences caused by random (non-matched) group assignment. Reducing these errors increases internal validity and allows for detecting smaller effects. On

9 Maurer and Jandura (2009) report similar findings from an online-offline methodology experiment. 
the contrary, a quasi-experimental design requires a heterogeneous sample, so the independent variables vary in a broad range.

When pooling respondents from multiple homogeneous samples, it is likely that these samples are different, which results in a respondent pool that is more heterogeneous than each original sample. Social status and demographics often correlate with attitudes and other variables, and concerning them, data from the SoSci Panel show that heterogeneity only increases selectively: Gender distribution in the SoSci Panel is about $60 \%$ women and $40 \%$ men with little variation over time. Such a surplus of female respondents is not untypical in communications. As reference, articles in the Journal of Communication from 2012 that present data collected from convenience samples were screened for the samples' gender distribution. On average, $58 \%$ of the respondents in the convenience samples are female ${ }^{10}$.

Regarding employment and age, the pool clearly shows more heterogeneity than a common student sample. $34 \%$ of the panelists still are in education (school or university), $46 \%$ are employed, and $8 \%$ work as freelancers ${ }^{11}$ in summer 2016 . The interquartile range of age is 25 to 48 years. Most heterogeneity is found regarding the panelists' domiciles: The panel's invitation and website are in German, consequently, $98 \%$ of the panelists live in Germany (84\%), Austria (11\%), or Switzerland (3\%); within Germany, the panelists' geographic distribution is similar to the populations' distribution ${ }^{12}$. Although there is a website to register for the panel, most panelists $(95 \%)$ join the pool after completing an academic questionnaire. It is not daring to expect that most of these surveys use convenience samples that likely include students and their acquaintances (student-recruited sample). Consistently, the pool's formal education level is nearly as homogeneous as one would expect from a student sample: Four out of five panelists have matriculation standard or higher education ${ }^{13}$. While people with lower education could be addresses for distinct studies, the majority of studies will lack educational heterogeneity.

Reproducibility. A sample that is randomly drawn from a pool will reproduce the pool's composition within statistical selection error. If the pool's structure is stable over time, this allows samples with reproducible structures (Meltzer et al., 2012). Although replication is limited by pool fluctuations (nearly one fourth of the participants in the SoSci Panel was replaced in 2016 due to removal of inactive addresses) and learning effects, convenience pools still have advantages re-

$10 N=30$, four studies do not disclose the gender relation. This margin grows to $62 \%$, if four studies conducted under special conditions are removed: Two studies on computer gaming and twitter, one study researching protesters during the Arab spring, one study conducted in schools in Tanzania.

11 Further occupations are: $5 \%$ retired, 2\% unemployed, $2 \%$ homemakers, 3\% occupied with something "other" ( $n=80480,86 \%$ disclosing their occupation).

12 Figures from 09/2013, based on panelists who specify their home country ( $n=82207,78 \%$ ). Compared to official statistics (Statistisches Bundesamt [Federal Statistical Office], 2012; Statistik Austria, 2012; Bundesamt für Statistik BFS [Federal Statistical Office], 2012a, 2012b) Germans and Austrians are overrepresented (GER: $86 \%$ vs. $84 \%$, AT: $11 \%$ vs. $9 \%$ ) while German-speaking Swiss are under-represented (3\% vs. $5 \%$ ) within the German-speaking countries. Within Germany, the ten main postal code areas are covered with deviations of $\pm 25 \%$ with an exception for the area around Dresden and Leipzig (code area 0$)$ that is over-represented by $55 \%$ (13\% vs. $8 \%$ panelists from Germany).

$131 \%$ no formal graduation, $4 \%$ elementary school, $12 \%$ secondary education certificate, $40 \%$ matriculation standard, $43 \%$ higher education, $1 \%$ other $(87 \%$ of the panelists disclose their formal education, $N=97879$ ). 
garding reproducible samples: First, given a large pool, more studies will draw their samples from the same population. Second, it is good practice to state the convenience pool from which a sample was drawn, while it is uncommon to disclose the university where a student sample was recruited.

Sample size. The sample size of convenience samples described in the Journal of Communication in 2012 ranges from 19 to 1607 ( $M=355, M d n=202$, $N=34$ articles). The largest sample yet realized through the SoSci Panel resulted in 11201 completed questionnaires (Leiner, 2016), but typically, samples are much smaller: The effective sample size in 2015/2016 ranges from 104 to 2072 $(M=662, M d n=493, N=27 \text { reports from researchers })^{14}$. Obviously, research designs that require large samples (e.g., to research small effects or to scrutinize interaction effects in an experiment) will benefit most from a convenience pool.

Response speed. Availability and response speed of convenience samples may vary in a broad range. A student sample is usually available on the same day (except during vacation), while it may take weeks to recruit and interview a snowball sample. Experience from the SoSci Panel suggests that response in a convenience pool takes some time, but is very reliable: Two thirds ${ }^{15}(67 \%)$ of the completed questionnaires arrive within 24 hours, but it takes another week to collect $95 \%$ of the responses (Figure 1). Weekends, vacation, and probably also delightful weather were observed to cause additional delays.

\section{Figure 1: Delay between invitation and participation}

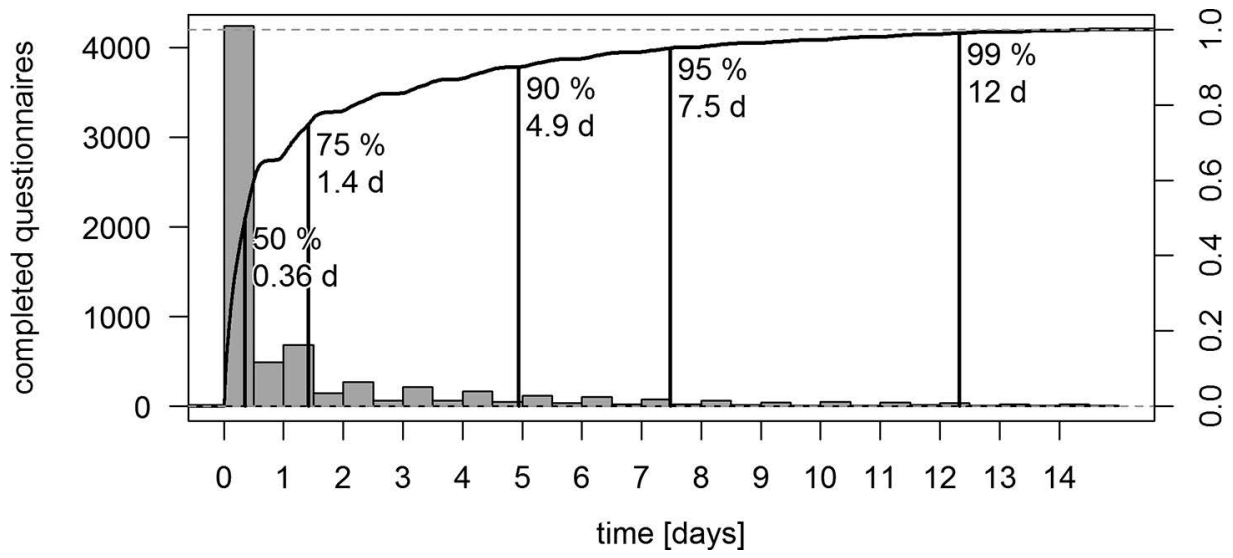

Notes: The gray bars show the number of questionnaires started in each time frame (left scale), the black line represents the cumulative responses (right scale). The figure is based on data collected for an invitation sent over a period of one year, every time addressing different panelists (07/19/2011 to 07/12/2012, 9 am Tuesday or Thursday, 45,117 invitations overall), $N=7080$ completed questionnaires. Each day's first bar is 9 am to 9 pm (daytime), each second bar is 9 pm to 9 am (nighttime).

14 This statistic is based on summaries from the researchers (mandatory since 06/2012). Technical recordings of invitation clicks are similar, but (a) include studies for which the researchers did not provide a summary and (b) include respondents that did not complete the questionnaire: Range 254 to $4008, M=1004, M d n=792, N=55$.

15 Invitations from the SoSci Panel are valid for 14 days. Therefore, $100 \%$ is the number of responses received within this limitation. 
Multiple survey waves. Longitudinal research designs can offer rich information - yet, collecting data throughout multiple survey waves is the exception rather than the rule in social research. Often, practical problems prevent longitudinal surveys: First, the initial sample may be unavailable, if there is a considerable time lag between the waves. In a non-student convenience sample, even a follow-up measure after few days may be impossible. A convenience pool may be the recruitment of choice, just for the reason, that respondents are available at a later point of time.

Second, costs and efforts increase disproportionately as non-responses in subsequent waves require larger initial samples. The additional costs due to interwave drop-outs depend on the type of sample: Undergraduate students participating in a study for credit points will show a great inter-wave loyalty. The all-wave response rate of volunteers recruited from a mailing list will likely be unspeakable. In the SoSci Panel, the additional sample size required for two-wave surveys was found to be quite consistent: To achieve the desired same sample size, about $70 \%$ more invitations than in a one-wave survey need to be sent. The increase is about the same for every further wave (Table 4).

Table 4: Response rates (completed questionnaires) in multiple-wave surveys

\begin{tabular}{|c|c|c|c|c|c|c|}
\hline Study & $\begin{array}{c}\text { Invitations } \\
\text { sent }\end{array}$ & $\begin{array}{c}\text { Time } \\
\text { lag }\end{array}$ & $\begin{array}{c}\text { Wave } \\
1 \\
\end{array}$ & $\begin{array}{l}\text { Waves } \\
1 \text { to } 2 \\
\end{array}$ & $\begin{array}{l}\text { Waves } \\
1 \text { to } 3 \\
\end{array}$ & $\begin{array}{l}\text { Waves } \\
1 \text { to } 4 \\
\end{array}$ \\
\hline Preferences persistence & 6800 & $\begin{array}{c}6 \\
\text { months }\end{array}$ & $\begin{array}{l}1460 \\
(21 \%)\end{array}$ & $\begin{array}{r}817 \\
(12 \%)\end{array}$ & $\begin{array}{c}579 \\
(9 \%)\end{array}$ & $\begin{array}{l}403 \\
(6 \%)\end{array}$ \\
\hline Public opinion stability & 43369 & $\begin{array}{c}1,2 \text {, or } 3 \\
\text { months }\end{array}$ & $\begin{array}{l}7843 \\
(18 \%)\end{array}$ & $\begin{array}{l}4,780 \\
(11 \%)\end{array}$ & $\begin{array}{c}68 \\
(8 \%)\end{array}$ & $\begin{array}{c}\text { no } \\
\text { wave } 4\end{array}$ \\
\hline $\begin{array}{l}\text { Job-related stress (incl. in- } \\
\text { complete questionnaires) }\end{array}$ & 5000 & $\begin{array}{c}2 \\
\text { months }\end{array}$ & $\begin{array}{l}1064 \\
(21 \%)\end{array}$ & $\begin{array}{r}618 \\
(12 \%)\end{array}$ & $\begin{array}{c}\text { no } \\
\text { wave } 3\end{array}$ & $\begin{array}{c}\text { no } \\
\text { wave } 4\end{array}$ \\
\hline $\begin{array}{l}\text { Election expectations } \\
\text { (esp. short questionnaire) }\end{array}$ & 4000 & $\begin{array}{l}1 \text { to } 4 \\
\text { weeks }\end{array}$ & $\begin{array}{r}803 \\
(20 \%)\end{array}$ & $\begin{array}{r}518 \\
(13 \%)\end{array}$ & $\begin{array}{c}418 \\
(10 \%)\end{array}$ & $\begin{array}{c}334 \\
(8 \%)\end{array}$ \\
\hline
\end{tabular}

Notes: Longitudinal surveys conducted in the SoSci Panel between 2011 and 2013. The first wave's return quote divided by a later wave's return quote tells the amount of additional invitations required to achieve the same response like in wave 1.

Third, anonymity may become an issue, when the answers of individual respondent collected in different survey waves shall be matched. A solution often applied to printed questionnaires is the personal code - an alphanumerical code created from personal data (e.g., concatenating the second character of the mother's first name, the last digit of birth year, etc.). Although such a code could ensure a good degree of anonymity, it increases interview burden and wrong or duplicate codes cause problems in larger samples. A more reliable solution becomes possible, if a convenience pool is organizationally separated from the researcher. The SoSci Panel acts as a depositary for the respondents' identity: It generates and stores a unique random code for each respondent. This code, but not the identity of the panelist, is transmitted to the researcher's questionnaire in each wave. After the survey's last wave has finished, the random code is deleted, and the respondent 
will have a new random code for other surveys. Such a procedure avoids duplicate codes, typing errors, and additional survey burden.

Experienced respondents. A significant difference between non-student convenience samples, student samples, and a convenience pool is the respondents' experience. Respondents from non-student samples are usually unknowledgeable of social research methods and most of them have never before completed a scientific questionnaire. Conversely, even undergraduate students often have heard about experimental designs and testing of hypotheses. Respondents from a convenience pool learn from the post-hoc information about experimental deceptions and/or from result summaries received in thanks for completing a questionnaire. In the SoSci Panel, the researchers indeed commit to publishing a short summary on their findings on the panel's website. An advantage of surveying experienced respondents is them being familiar with common response formats, so they can focus their attention on the questions. They may also have thought about their personality and attitudes in earlier surveys, and they are fast in doing questionnaires (Appendix). Yet, there are drawbacks that may render trained respondents unacceptable for a research project: They may show a different response behavior (Olson \& Bilgen, 2011; Toepoel, Das, \& van Soest, 2009), they may expect that (stimulus-)texts read in a questionnaire are not authentic, they may discover obfuscated treatments in an experiment, and some respondents will even correctly guess the hypotheses underlying a study. Meltzer, Naab, and Daschmann (2012) show that hypotheses guessing can significantly bias the findings drawn from questionnaire data - free text answers about these guesses can control this problem only to a limited degree.

In response to question $3(\mathrm{Q} 3)$, some considerations are necessary when deciding to use a convenience pool, a student sample, or another convenience sample: (1) Does the research question allow for an online questionnaire? (2) Does testing of the hypotheses require a heterogeneous sample or will a homogeneous sample show effects more clearly? (3) What sample size is required to test the hypothesized effects? (4) Are there theoretical reasons that require response within a specific time frame? (5) Does the research design require multiple survey waves? (6) Will respondents' experience with social research rather help or hinder the research interests?

Beyond these considerations, convenience pools have advantages regarding sample structure replication, and drawing respondents from a pool may change the interpretation of statistical significance ( $\mathrm{p}$-values): When a non-experimental design is employed on a convenience sample, significance tests are usually invalid, because the convenience sample is no probability sample of any (known) general population. But if respondents are randomly drawn from a pool, significance tests tell, whether we can generalize a test result to the pool population - or if the observation is more likely a result of statistical noise. Any further generalization to the national or any other population, of course, remains a logical inference.

Another application is gained by the fact that a convenience pool inexpensively allows for longitudinal survey designs: Samples from a convenience pool can effectively enrich research based on representative samples. Scherr and Reinemann (2013) first collected data from a probability-based cross-section sample to test correlations, and recruited another sample from the SoSci Panel at the same time 
to collected longitudinal data and test causality of the same correlations. Ganser and Riordan (2013) researched (elusive) election expectations in a representative sample, but were also interested in how these expectations develop over time. Self-evidently, timing of data collection had to be synchronized between the representative sample and the longitudinal convenience sample.

\section{When to organize a convenience pool}

Many social researchers consider it convenient, having a convenience pool at call - especially, when the pool has an adequate size, respondents are motivated, and there is little organizational overhead. Based on data and experience from the SoSci Panel, this section will discuss prerequisites and efforts regarding the decision whether it is a good idea to start a convenience pool under specific conditions. Additional literature on how to maintain an access panel is, of course, valid for convenience pools as well. Specifically literature on panelist motivation (Bosnjak, Tuten, \& Wittmann, 2005; Brüggen \& Dholakia, 2010; Lund, Jones, \& Spanitz, 2009; Phillips, Woodward, Collins, \& O’Connor, 2002; Porst \& Briel, 1995; Vocino \& Polonsky, 2011), use of incentives (Göritz, 2004, 2008; Göritz \& Wolff, 2007; Göritz, Wolff, \& Goldstein, 2008; Singer \& Kulka, 2002; Singer, van Hoewyk, \& Maher, 1998; Zagorsky \& Rhoton, 2008), wear-out effects (Sandage, 1956), and panel attrition (Dennis \& Li, 2003; Lehnen \& Koch, 1974; Lund et al., 2009; Winer, 1983).

Software. When the SoSci Panel was founded, the available software for pool management either exceeded the project's (non-)budget or lacked necessary features (for a review of current panel software see Macer, 2014). Therefore, the software OpenPool was developed and made available to other researchers under open source license (Leiner, 2012). Most tasks necessary to manage a respondent pool could be automated: Double opt-in and collection of master data during the registration, a yearly update of the master data, automatic deletion of email addresses that have become invalid (bounces), screening for inactive panelists, and features to allow panelists updating or deleting their data. The pool administrator's job then is to specify the text of an invitation mailing, the date and time when to send it, and the number and characteristics of the panelists to receive the invitation. Relevant features of OpenPool include support for multi-wave surveys, subsample selection by demographics, survey-load limitations per panelist, surveyload balancing, and live statistics on actual response per survey. A shortcoming of the current OpenPool version is the lack of support for the peer review process, which has become a main driver of efforts regarding the SoSci Panel.

Further efforts. The costs for an appropriate Internet server have constantly decreased during recent years. Today they are negligible, even if the server must comply with strict privacy laws. As the pool software requires little server resources, it may even run on a web server that is already handling other services. Nonetheless, security and privacy issues may require some efforts - for example, setting up encryption (SSL/HTTPS) and common security measures (firewall, regular or automated server updates, backups, etc.). In total, there is little cost for server and software, and the hours of maintaining the pool itself have found to be 
limited, as well: Even in the SoSci Panel, only two or three respondents send an email during an average month - reporting registration problems (e.g., an email client that won't display the email correctly), wanting their addresses deleted from the pool (and did not find the appropriate hyperlink in the recent invitation), and/or complaining about a questionnaire just sent to the pool (although most such concerns are directly sent to the researcher).

Response rate. In probability-based or quota samples, any self-selection of respondents could cause biases. Therefore, the response rate is an indicator for the quality of such samples. In a convenience sample, the response rate is meaningless regarding self-selection (Schonlau et al., 2002): If a sample is not representative of the population, even a response rate of $100 \%$ does not allow for any more generalization than a response rate of $5 \%$. The response rate rather obfuscates existing biases (compared to whatever is the relevant population) in a convenience sample: There is no guarantee that a sample recruited with $99 \%$ response rate (e.g., students earning credit points) is less biased than another sample recruited with $1 \%$ response rate (e.g., self-recruited users of a social networking site). Nonetheless, the response rate in a convenience pool has a practical dimension: It tells how many completed questionnaires the pool can "produce", i.e., how many studies may be facilitated by the pool.

Researchers using the SoSci Panel report an effective response rate of about $20 \%$ (see Table 4, first wave). Other than the effective response rate, the CTR (clickthrough-rate, i.e. the rate of panelists who click the hyperlink in an invitation email) is automatically measured by the panel software ${ }^{16}$. The CTR includes respondents who quit or do not even start responding. The average CTR is 22\% ( $N=991102$ non-follow-up invitations sent between 09/2011 and 10/2015) with variations per study topic and season (between 20\% during summer break and 25\% in January, after the Christmas break); on weekends and official holidays a significant decrease of CTR was observed. When corrected for the monthly variation, the CTR per invitation varies by about $S D= \pm 6.5 \%$ (IQR $=18 \%$ to $25 \%, N=442$ invitation mailings with 500 or more recipients, sent between 09/2011 and 10/2015).

Registration rate. Will a convenience pool attract a sufficient number of panelists within an acceptable time frame? The answer depends on the number of contacts (people seeing the invitation form) and the probability of pool enrollment per contact (registration rate). The former can be easily estimated and the SoSci Panel provides experience about the latter, given that the invitation form is shown subsequently to online questionnaires. In 2015/2016 about 1000 academic surveys were initiated on SoSci Survey each month, and 4 in 10 displayed the panel invitation form. That made 62500 interviewees per month to see the invitation, and 2430 who actually registered for the panel on an average month (double-opt-in rate of $3.9 \%$ ).

16 The SoSci Panel collects detailed anonymous statistics on survey participation since 09/2011. Whenever a mailing is sent, a unique entry is created for each addressee. After a period of 14 days, when the entry is deleted, the response status (did the addressee click the hyperlink in the invitation or not) is stored together with other data (e.g., the number of invitations sent to this panelist in the recent 12 months, the time between the recent invitation and that before, etc.). 
A recruitment rate of $3.9 \%$ may seem disappointing, given the effort spent on finding respondents for a survey. To realize a sample of 500 respondents from the pool, 2500 or more panelists must have registered (given $20 \%$ response rate). So, the invitation form must be shown to 64000 respondents, before a sufficient pool size is achieved - that is more than 200 surveys with 300 respondents each. These numbers demonstrate that a convenience pool is no personal option, but shall be run by an institution. Kindly asking all students and researchers from a faculty to add an invitation form to their questionnaires will easily reach a number of 200 surveys. And two more points put the SoSci Panel's recruitment rate into perspective: First, many of the 2500 panelists will stay in the pool for years and the pool will grow further. Still, there will be drop-out to expect (in the SoSci Panel this is about one quarter per year). Second, most respondents have never heard about the SoSci Panel before joining it. An invitation branded by a well-known university or organization may increase the recruitment rate dramatically.

Gains of patience. Not only will the size of a convenience pool increase, its structure will also change over time. During the first few years, the pool is comprised of respondents who would have been easily available, anyway - most of them were part of convenience samples when they are recruited for the pool. Usually these panelists are somewhere between 20 and 30 years, i.e., they join the pool when their life is about to change. Within some years, students and their friends become employees and managers in time-consuming jobs, parents who devote lots of their time to the family, or they leave the country. But they will often remain in the pool. So, a convenience pool maintained for some years provides a chance to address respondents from demographic groups which would be otherwise difficult to reach. This transformation, of course, does not apply to other attributes, like the social background and the formal education.

Survey load. The third factor driving the pool's efficiency is the number of invitations that respondents will accept before ignoring further emails. There is a strict limit of four invitations per year in the SoSci Panel, but the data collected on survey participation allows some interesting insights. The click-through-rate (CTR) of panelists who did not receive any invitation to another study within the recent 12 months, is $27 \%$. This figure constantly decreases with one $(22 \%)$, two and three (21\% each) previous invitations $(N=991102$ non-follow-up invitations sent between 09/2011 and 10/2015). Four invitations seem no definite limit at all. On the contrary, some practitioners argue that panelists' loyalty may be lost, if there is no contact for a while. Such a long-term effect is found in the SoSci Panel as well - but its size is smaller than the effect of previous invitations: If the most recent invitation was sent 9 to 12 months ago, the CTR is $19.6 \%$ $(n=54,051)$ - compared to $21.8 \%(n=386,872)$ if another invitation has been sent during the recent three months ${ }^{17}$.

17 Obviously, the time since the last invitation is not independent from the number of invitations received during the last 12 months $(r=.17)$. When controlled for the number of recent invitations, the effect of the time lag on participation probability increases, but is still weak (binomial regression on participation, model $1: B_{1}=-0.021$ per month without an invitation, model 2 with previous invitations: $B_{1}=-0.033$ per month, $B_{2}=-0.126$ per previous invitation, $N=554271$ unique invitations). 
The SoSci Panel's limit of four invitation emails per year was chosen arbitrarily. But one should consider two drawbacks, before trying and find the optimal invitations rate to "produce" most questionnaires per panelists. First, we have to acknowledge that there probably is a large interpersonal variation, regarding the "pain threshold". Raising the rate of emails may not only increase productivity, but also chase away certain groups of respondents. Second, sending more invitations will also enlarge the chance that emails from the pool are automatically identified as SPAM (unwanted emails) by email providers, which will significantly decrease the effective response rate.

Topic diversity. There will be at least two benefits if questionnaires on different topics are sent out through the pool: It is more interesting for the panelists to stay, and a topical learning effect is avoided. The latter decreases the disadvantage of experienced respondents. Therefore, it is advantageous when different researchers, working on different topics, have access to the convenience pool. As a perspective, the cooperation of different convenience pools may afford more diversity and further advantages as well.

Response to question $4(\mathrm{Q} 4)$. There are at least two premises for starting a successful convenience pool: (1) Access to potential panelists, for example through a multitude of online surveys that show the invitation form, and (2) sufficient patience. Given an unknown pool "brand", the invitation form must be presented to nearly 65000 people who are generally willing to do online questionnaires, before an effective sample of 500 respondents can be realized by means of the pool. Both premises suggest placing the organization of a convenience pool into the hands of a research institution, not a single researcher. The long-term benefits of maintaining a convenience pool are obvious: Larger samples and/or more studies become possible, and the panelists grow older and cover a growing demographic range.

An important finding stemming from the SoSci Panel is that the greatest challenge of maintaining a large convenience pool is not the technical setup or the daily communication. Rather, it is the management of studies that seek sending online questionnaires to the panelists, especially when external researchers are granted access to the pool (e.g., to increase diversity). In the SoSci Panel, which surely is an extreme case, a peer review process was established in 2012 to ensure an appropriate level of quality and to share the effort of quality control. Finally, the pool provider has a vested interest in keeping up the panelists' goodwill, because it is this goodwill that makes the respondents join a convenience pool and complete questionnaires.

\section{Discussion}

A large body of sociological and psychological knowledge was gained upon convenience samples. While the weaknesses and limitations of convenience samples are well known, the broad range of fundamental research conducted in social sciences would be impossible without them. Often, an analysis of costs and benefits will even favor a convenience sample over a nationally representative sample. This paper presents an enhancement of the traditional concept of convenience samples: Large convenience pools collecting the email addresses of Internet sur- 
vey respondents. The SoSci Panel is an implementation of this concept in the German-speaking area, proving its service for non-commercial academic research projects for free. This paper discusses the application of convenience samples in general (Q1) and presents insights from the SoSci Panel to researchers who consider using a convenience pool for their own research $(\mathrm{Q} 2 / \mathrm{Q} 3)$ or creating a convenience pool by themselves (Q4). Samples from a convenience pool are found to be most useful if hypotheses are to be tested and the data is to be collected through an online survey, if a large sample with some heterogeneity is required, and/or if a longitudinal research design demands multiple survey waves. Starting their own convenience pool may be most fruitful for faculties that conduct a lot of online surveys, anyway.

If setting up or using a convenience pool is considered, one point is vital: A sample drawn from a convenience pool will not exceed the basic limitations of convenience samples. The example of the SoSci Panel illustrates just the opposite: Each panelist there has accomplished at least three steps of self-selection before starting the first questionnaire sent from the panel: (1) They have likely self-recruited for another study before, (2) entered their email address in an onlineform, confirmed pool participation during the opt-in process, and (3) decided to follow the panel's invitation to another questionnaire. Therefore, a convenience pool cannot replace a well-tended commercial access panel or even a probabilitybased sample (Göritz, 2007; Göritz, Reinhold, \& Batinic, 2002). Even when a quota sample from a convenience pool meets the population's demographic margins, it's probably still biased in other aspects that are important for social research questions: Convenience pools and their samples have significant strengths and justified uses, but shall not be considered as an option for representative samples. Yet, the combination of representative samples with convenience samples has been shown to be very fruitful.

A convenience pool is most useful in fluently providing large and heterogeneous convenience samples. At the same time, it increases the transparency and reproducibility of sample recruitment: While little is known about the "undergraduate students" and other convenience samples, each study conducted in a convenience pool contributes to the knowledge about its members. To some degree, this counters the criticism that biases that are unknown to the reader may possibly account for a study's results.

\section{Appendix}

The following hypotheses were tested for differences between a convenience quota sample (OC), recruited by a snowball procedure, and respondents from the SoSci Panel (SP).

1. Trained pool respondents will complete the questionnaire faster than untrained respondents. This hypothesis is well supported with an average difference of 8.2 minutes between untrained snowball respondents and trained respondents from the SoSci Panel $\left(M_{\mathrm{OC}}=27.2 \mathrm{~min} ., n_{\mathrm{OC}}=200, M_{\mathrm{SP}}=19.5 \mathrm{~min}\right.$., $n_{\mathrm{SP}}=318$, 
$t=9.43, \mathrm{p}<.001)^{18}$. The difference remains significant when controlling for age and individually different questionnaire length due to filter questions (regression, $\left.B=7.1 \mathrm{~min} ., p_{\mathrm{B}}<.001\right)$.

2. Given the quota schedule, it is no surprise that demographic variance is larger in the snowball sample, especially regarding age. But the snowball sample is restricted regarding region and relevant peers - therefore the panelists should provide more variance regarding attitudes. The ice breaker question "For the next 12 months, do you have hopes? Or instead do you have fears?" is suitable to test this hypothesis. It is not supported. On the contrary, the snowball shows slightly more variance than the pool $\left(S D_{\mathrm{OC}}=1.05, S D_{\mathrm{SP}}=1.00, p<.05\right.$, Levene test $)$. There is no relevant or significant correlation between age and hopes/fears that would explain this difference. The questionnaire further asked for topic interests on politics, sports, local stories, and boulevard. No differences regarding variance were found for these questions.

3. A common indicator of data quality is item non-response (Barge \& Gehlbach, 2012; Shin, Johnson, \& Rao, 2012). In the SoSci Panel the researcher has merely no contact to the respondents and cannot create as much personal commitment as in most other convenience sample strategies. Therefore, one would expect less data quality (higher item non-response) in the panel compared to the snowball subsample. A tendency in the opposite direction was found $\left(M_{\mathrm{OC}}=3,3 \%, M_{\mathrm{SP}}=3,0 \%, n_{\mathrm{OC}}=226, n_{\mathrm{SP}}=344, t=0.98\right.$, n.s. $)$. Yet, this does not prove equal data quality in the pool: Training may also result in missing less items by mistake and Toepoel, Das, and van Soest (2009) show that panelists may tend to more satisficing (Krosnick, 1991).

4. Convergent validity is another indicator for data quality (Scherpenzeel, 2008), because it shows that questions were not answered randomly. Scale consistency is one option for assessing consistent answering behavior (Börkan, 2010). Two 7-point short scales (4 items on civil engagement and 3 items on the big-five dimension openness to experience) allowed a test whether trained panelists or personally committed participants provide more in-scale consistency. The panelists perform slightly better, regarding both scales' Cronbach's alpha, but the difference does not approach significance. Of course, this non-significant difference could indicate satisficing instead of data quality, as well.

The more common option to measure convergent validity is the correlation between distinct but related constructs. The participants were not only asked for their topic interest but also if they found this topic relevant. Correlations between interest and relevance judgment are between .63 (politics) and .83 (sports). Again, there are no significant differences between the subsamples' correlation coefficients, except for local topics $\left(r_{\mathrm{oc}}=.77, r_{\mathrm{SP}}=.68, n_{\mathrm{OC}}=222, n_{\mathrm{SP}}=345, p<.05\right)$, which may be an effect of the differences in the subsamples' average age.

18 Regarding overall survey duration there is a significant percentage of outliers, e.g., people who seem to spend five minutes on one page because they check their email while doing the questionnaire. $9.4 \%$ outliers were excluded from this analysis with no significant group difference $\left(\mathrm{Chi}^{2}=1.48\right.$ with Yates correction, n.s. $)$. 
5. Discriminant validity can distinguish satisficing from valid correlations (Krosnick, 1991). If panelists only achieved the same in-scale and inter-construct correlations by satisficing, we should observe a larger correlation between unrelated constructs as well. Again, topic interests prove useful, because they should be uncorrelated to another, except for politics and local topics. Correlations are between -.30 and +.14 and there is no systematic tendency or significant difference between the subsamples - except for politics and boulevard which are more negatively correlated in the panel $\left(r_{\mathrm{OC}}=-.14, r_{\mathrm{SP}}=-.30, p<.05\right)$. This correlation, however, is plausible and does not validly indicate discriminant (in-)validity.

6 . The amount of text provided in open ended questions is a common data quality indicator (Kwak \& Radler, 2002; Schaefer \& Dillman, 1998; Shin et al., 2012). One question asked the respondents to provide a word definition. $18 \%$ of the questionnaires from the snowball subsample contained an answer, and $22 \%$ from the panel subsample $\left(\mathrm{Chi}^{2}=1.06\right.$, n.s. $)$. If an answer was given, its length was 80.4 characters/10.7 words (OC) and 94.0 characters/12.8 words (SP), respectively. This group difference as well as the difference including void answers (14.6 vs. 20.4 characters) does not approach significance.

\section{References}

Asch, S. E. (1963). Effects of group pressure upon the modification and distortion of judgements. In H. Guetzkow (Ed.), Groups, leadership and men. Research in human relations (pp. 177-190). New York, NY: Russel \& Russel.

Barge, S., \& Gehlbach, H. (2012). Using the theory of satisficing to evaluate the quality of survey data. Research in Higher Education, 53(2), 182-200. doi:10.1007/s11162-0119251-2

Basil, M. D. (1996). The use of student samples in communication research. Journal of Broadcasting \& Electronic Media, 40(3), 431.

Beck, A. T., Ward, C. H., Mendelson, M., Mock, J., \& Erbaugh, J. (1961). An inventory for measuring depression. Archives of General Psychiatry, 4(6), 561. doi:10.1001/ archpsyc.1961.01710120031004

Berkowitz, L., \& Donnerstein, E. (1982). External validity is more than skin deep: Some answers to criticisms of laboratory experiments. American Psychologist, 37(3), 245-257.

Bischof, N. (2009). Psychologie: Ein Grundkurs für Anspruchsvolle [Psychology: A basic course for the ambitious] (2 $2^{\text {nd }}$ ed.). Stuttgart: Kohlhammer.

Börkan, B. (2010). The mode effect in mixed-mode surveys. Social Science Computer Review, 28(3), 371-380. doi:10.1177/0894439309350698

Bosnjak, M., Tuten, T. L., \& Wittmann, W. W. (2005). Unit (non)response in Web-based access panel surveys: An extended planned-behavior approach. Psychology \& Marketing, 22(6), 489-505. doi:10.1002/mar.20070

Brüggen, E., \& Dholakia, U. M. (2010). Determinants of participation and response effort in Web panel surveys. Journal of Interactive Marketing, 24(3), 239-250. doi:10.2139/ ssrn. 1509763

Bundesamt für Statistik BFS. (2012a). Provisorische Ergebnisse zur Bevölkerungsentwicklung der Schweiz im Jahr 2011: Bevölkerungswachstum setzt sich fort [Provisional results 
on changes in the population in the Swiss in 2011]. Neuchâtel. Available online: http:// www.bfs.admin.ch/bfs/portal/de/index/news/04/01.Document.155075.pdf

Bundesamt für Statistik BFS. (2012b). Strukturerhebung der eidgenössischen Volkszählung 2010: Ein Fünftel der Bewohnerinnen und Bewohner ist konfessionslos [Structural description of the confederate population census 2010]. Neuchâtel. Available online: http:// www.bfs.admin.ch/bfs/portal/de/index/news/04/01.Document.159960.pdf

Collani, G. von, \& Herzberg, P. Y. (2003). Eine revidierte Fassung der deutschsprachigen Skala zum Selbstwertgefühl von Rosenberg [Revised version of the German self-esteem scale by Rosenberg]. Zeitschrift für Differentielle und Diagnostische Psychologie, 24(1), 3-7. doi:10.1024//0170-1789.24.1.3

Courtright, J. A. (1996). Rationally thinking about nonprobability. Journal of Broadcasting \& Electronic Media, 40(3), 414.

Crippa, J. A. S., Lima Osório, F. de, Del-Ben, C. M., Filho, A. S., Silva Freitas, M. C. da, \& Loureiro, S. R. (2008). Comparability between telephone and face-to-face structured clinical interview for DSM-IV in assessing social anxiety disorder. Perspectives in Psychiatric Care, 44(4), 241-247. doi:10.1111/j.1744-6163.2008.00183.x

Dennis, J. M., \& Li, R. (2003). Effects of panel attrition on survey estimates. Presentation at the 2003 annual meeting of the American Association for Public Opinion Research, Nashville, TN. Available online: http://www.knowledgenetworks.com/ganp/docs/ kn\%20panel\%20attrition\%20paper.pdf

Donker, T., van Straten, A., Marks, I., \& Cuijpers, P. (2010). Brief self-rated screening for depression on the Internet. Journal of Affective Disorders, 122(3), 253-259. doi:10.1016/j.jad.2009.07.013

Dooley, L. M., \& Lindner, J. R. (2003). The handling of nonresponse error. Human Resource Development Quarterly, 14(1), 99-110. doi:10.1002/hrdq.1052

Farrokhi, F., \& Mahmoudi-Hamidabad, A. (2012). Rethinking convenience sampling: Defining quality criteria. Theory and Practice in Language Studies, 2(4), 784-792. doi:10.4304/tpls.2.4.784-792

Ferber, R. (1977). Research by convenience: Editorial. Journal of Consumer Research, 4(June), 57-58.

Festinger, L., \& Carlsmith, J. M. (1959). Cognitive consequences of forced compliance. Journal of Abnormal and Social Psychology, 58, 203-210.

Fowler, F. J. (2006). Survey research methods (3 ${ }^{\text {rd }}$ ed.). Applied social research methods series: Vol. 1. Thousand Oaks, CA: Sage.

Ganser, C., \& Riordan, P. (2013). Vergleich von SoSci-Daten (Online) mit einer Zufallsstichprobe (Telefon) [Comparison of data from SoSci (online) and a probability sample (telephone)]. Unpublished Manuscript.

Göritz, A. S. (2004). The impact of material incentives on response quantity, response quality, sample composition, survey outcome, and cost in online access panels. International Journal of Market Research, 46(3), 327-345.

Göritz, A. S. (2007). Using online panels in psychological research. In A. N. Joinson, K. McKenna, T. Postmes, \& U.-D. Reips (Eds.), The Oxford handbook of Internet psychology (pp. 473-485). Oxford: Oxford Univ. Press.

Göritz, A. S. (2008). The long-term effect of material incentives on participation in online panels. Field Methods, 20(3), 211-225. doi:10.1177/1525822X08317069 
Göritz, A. S., \& Moser, K. (2000). Repräsentativität im Online Panel [Representativeness in online panels]. Der Markt, 155(4), 156-162. doi:10.1007/BF03033955

Göritz, A. S., Reinhold, N., \& Batinic, B. (2002). Online panels. In B. Batinic, U.-D. Reips, M. Bosnjak, \& A. Werner (Eds.), Online social sciences (pp. 29-51). Seattle, Wash: Hogrefe \& Huber.

Göritz, A. S., \& Wolff, H.-G. (2007). Lotteries as incentives in longitudinal Web studies. Social Science Computer Review, 25(1), 99-110. doi:10.1177/0894439306292268

Göritz, A. S., Wolff, H.-G., \& Goldstein, D. G. (2008). Individual payments as a longerterm incentive in online panels. Behavior Research Methods, 40(4), 1144-1149. doi:10.3758/BRM.40.4.1144

Gravetter, F. J., \& Forzano, L.-A. B. (2009). Research methods for the behavioral sciences ( $3^{\text {rd }}$ ed.). Belmont, CA: Wadsworth Cengage.

Hargittai, E. (2015). Is bigger always better? Potential biases of big data derived from social network sites. The ANNALS of the American Academy of Political and Social Science, 659(1), 63-76. doi:10.1177/0002716215570866

Henrich, J., Heine, S. J., \& Norenzayan, A. (2010). The weirdest people in the world? Behavioral and Brain Sciences, 33(2-3), 61-83. doi:10.1017/S0140525X0999152X

Houde, S. C. (2002). Methodological issues in male caregiver research: an integrative review of the literature. Journal of Advanced Nursing, 40(6), 626-640. doi:10.1046/ j.1365-2648.2002.02423.x

Infratest dimap. (2012). Sonntagsfrage [Voting poll]. Available online: http://www.infratest-dimap.de/umfragen-analysen/bundesweit/sonntagsfrage/

Krosnick, J. A. (1991). Response strategies for coping with the cognitive demands of attitude measures in surveys. Applied Cognitive Psychology, 5(3), 213-236. doi:10.1002/ acp. 2350050305

Kwak, N., \& Radler, B. (2002). A comparison between mail and Web surveys: Response pattern, respondent profile, and data quality. Journal of Official Statistics, 2(18). Available online: http://www.barold.com/www/JOS\%20article.pdf

Lang, A. (1996). The logic of using inferential statistics with experimental data from nonprobability samples: Inspired by Cooper, Dupagne, Potter, and Sparks. Journal of Broadcasting of Electronic Media, 40(3), 422-430. doi:10.1080/08838159609364363

Lehnen, R. G., \& Koch, G. G. (1974). Analyzing panel data with uncontrolled attrition. Public Opinion Quarterly, 38(1), 40-56.

Leiner, D. J. (2012). OpenPool. Munich. Available online: https://sourceforge.net/projects/ openpool/

Leiner, D. J. (2016). Stabilität öffentlicher Meinung. Wie der Charakter einer Streitfrage den Einfluss der Medien begrenzt [Stability of public opinion. Do issue attributes moderate media effects]. PhD thesis. Wiesbaden, DE: Springer VS. doi:10.1007/978-3-658-12285-0

Loosveldt, G., \& Sonck, N. (2008). An evaluation of the weighting procedures for an online access panel survey. Survey Research Methods, 2(2), 93-105.

Lund, C. M., Jones, V. S., \& Spanitz, S. (2009). Effects and influences of motivation on trained panelists. Food Quality and Preference, 20(4), 295-303. doi:10.1016/j.foodqual.2009.01.004

Lunsford, T. R., \& Lunsford, B. R. (1995). The research sample, part I: Sampling. Journal of Prosthetics and Orthotics, 7(3). Available online: http://journals.lww.com/jpojournal/Fulltext/1995/00730/The_Research_Sample,_Part_I_Sampling.8.aspx 
Macer, T. (2014). Online panel software. In M. Callegaro, R. P. Baker, J. Bethlehem, A. S. Göritz, J. A. Krosnick, \& P. J. Lavraskas (Eds.), Online panel research: An interdisciplinary approach. Chichester: Wiley.

Marsden, P. V., \& Wright, J. D. (Eds.). (2010). Handbook of survey research (2 ${ }^{\text {nd }}$ ed.). Bingley: Emerald.

Marshall, M. N. (1996). Sampling for qualitative research. Family Practice, 13(6), 522526. doi:10.1093/fampra/13.6.522

Martinez-Ebers, V. (1997). Using monetary incentives with hard-to-reach populations in panel surveys. International Journal of Public Opinion Research, 9(1), 77-86.

Maurer, M., \& Jandura, O. (2009). Masse statt Klasse? Einige kritische Anmerkungen zu Repräsentativität und Validität von Online-Befragungen [Quantity instead of quality? Critical comments on representativeness and validity on online surveys]. In N. Jackob, H. Schoen, \& T. Zerback (Eds.), Sozialforschung im Internet. Methodologie und Praxis der Online-Befragung [Social research in the Internet. Methods and practice of online surveys]. Wiesbaden: VS/GWV.

McCombs, M. E., \& Shaw, D. L. (1972). The agenda-setting function of mass media. Public Opinion Quarterly, 36(2), 176. doi:10.1086/267990

Meltzer, C. E., Naab, T., \& Daschmann, G. (2012). All student samples differ: On participant selection in communication science. Communication Methods and Measures, 6(4), 251-262. doi:10.1080/19312458.2012.732625

Milgram, S. (1963). Behavioral study of obedience. Journal of Abnormal and Social Psychology, 67(4), 371-378.

Mook, D. G. (1983). In defense of external invalidity. American Psychologist, 38(4), 379_ 387. doi:10.1037/0003-066X.38.4.379

Newman, I., \& McNeil, K. A. (1998). Conducting survey research in the social sciences. Lanham: Univ. Press of America.

Nock, S. L., \& Guterbock, T. M. (2010). Survey experiments. In P. V. Marsden \& J. D. Wright (Eds.), Handbook of survey research (2 ${ }^{\text {nd }}$ ed., pp. 837-864). Bingley: Emerald.

O'Leary, Z. (2004). The essential guide to doing research. London: Sage.

Olson, K., \& Bilgen, I. (2011). The role of interviewer experience on acquiescence. Public Opinion Quarterly, 75(1), 99-114.

Pavlov, I. P. (1927). Conditioned reflexes: An investigation of the physiological activity of the cerebral cortex. Translated by G.V. Anrep. London: Oxford Univ. Press. Available online: http://psychclassics.yorku.ca/Pavlov/

Phillips, M., Woodward, C., Collins, D., \& O’Connor, W. (2002). Encouraging and maintaining participation in the Families and Children Survey: Understanding why people take part. London: Dept. for Work and Pensions. Available online: http://research.dwp. gov.uk/asd/asd5/WP6.pdf

Pöldinger, W. (1968). Die Abschätzung der Suizidalität: Eine medizinisch-psychologische und medizinisch-soziologische Studie [Estimating suicidal tendency. A medial-psychological and medical-sociological study]. Aktuelle Probleme in der Psychiatrie, Neurologie/Neurochirurgie: Vol. 1. Bern, Stuttgart: Huber.

Porst, R., \& Briel, C. von. (1995). Wären Sie vielleicht bereit, sich gegebenenfalls noch einmal befragen zu lassen?: oder: Gründe für die Teilnahme an Panelbefragungen [Would you perhaps agree another survey? or: Reasons for attending panel surveys] 
(ZUMA-Arbeitsbericht No. 95/04). Mannheim. Available online: http://nbn-resolving. de/urn:nbn:de:0168-ssoar-70231

Potter, W. J., Cooper, R., \& Dupagne, M. (1993). The three paradigms of mass media research in mainstream communication journals. Communication Theory, 3(4), 317-335. doi:10.1111/j.1468-2885.1993.tb00077.x

Potter, W. J., Cooper, R., \& Dupagne, M. (1995). Reply to Sparks's critique. Communication Theory, 5(3), 280-286. doi:10.1111/j.1468-2885.1995.tb00110.x

Potthoff, P., Heinemann, L. A., \& Güther, B. (2004). A household panel as a tool for costeffective health-related population surveys: validity of the "Healthcare Access Panel". German Medical Science, (2). Available online: http://www.ncbi.nlm.nih.gov/pmc/articles/PMC2703211/

Robson, C. (2011). Real world research: A resource for users of social research methods in applied settings ( $3^{\text {rd }}$ ed.). Chichester, West Sussex: Wiley.

Rookey, B. D., Hanway, S., \& Dillman, D. A. (2008). Does a probability-based household panel benefit from assignment to postal response as an alternative to Internet-only? Public Opinion Quarterly, 72(5), 962-984.

Rothschild, D. \& Wolfers, J. (2012). Forecasting elections: Voter intentions versus expectations. Available online: http://www.brookings.edu/ /media/Research/Files/Papers/2012/ $11 / 01 \% 20$ voter $\% 20$ expectations $\% 20$ wolfers/01\%20voter $\% 20$ expectations $\% 20$ wolfers. pdf

Ryan, H., Wortley, P. M., Easton, A., Pederson, L., \& Greenwood, G. (2001). Smoking among lesbians, gays, and bisexuals: a review of the literature. American Journal of Preventive Medicine, 21(2), 142-149. doi:10.1016/S0749-3797(01)00331-2

Salganik, M. J., \& Heckathorn, D. D. (2004). Sampling and estimation in hidden populations using respondent-driven sampling. Sociological Methodology, 34, 193-239. doi: $10.2307 / 3649374$

Sandage, C. H. (1956). Do research panels wear out? Journal of Marketing, 20(4), 397401.

Saumure, K., \& Given, Lisa M. (2008). Convenience sample. In The SAGE Encyclopedia of Qualitative Research Methods. Thousand Oaks, CA: Sage.

Schaefer, D. R., \& Dillman, D. A. (1998). Development of a standard E-Mail methodology: Results of an experiment. Public Opinion Quarterly, 62, 378-397. Available online: http://www.sesrc.wsu.edu/dillman/papers/1998/developmentofastandard.pdf

Scherpenzeel, A. (2008). Online interviews and data quality: A multitrait-multimethod study: Draft paper to be presented at the MESS Workshop, 22-23 August 2008. Zeist. Available online: http://www.centerdata.nl/export/sites/CentERdata/nl/TopMenu/Projecten/MESS/Scherpenzeel-2008-MESS_workshop-paper.pdf

Scherr, S., \& Reinemann, C. (2013). Media and mental health. Unpublished manuscript.

Schonlau, M., Fricker, R. D., \& Elliott, M. N. (2002). Conducting research surveys via Email and the Web. Santa Monica, CA: RAND. Available online: http://www.rand.org/ pubs/monograph_reports/MR1480

Schonlau, M., van Soest, A., Kapteyn, A., \& Couper, M. P. (2009). Selection bias in Web surveys and the use of propensity scores. Sociological Methods \& Research, 37(3), 291-318. doi:10.1177/0049124108327128 
Sell, R. L., \& Petrulio, C. (1996). Sampling homosexuals, bisexuals, gays, and lesbians for public health research. Journal of Homosexuality, 30(4), 31-47. doi:10.1300/ J082v30n04_02

Sherry, B., Jefferds, M. E., \& Grummer-Strawn, L. M. (2007). Accuracy of adolescent selfreport of height and weight in assessing overweight status. Archives of Pediatrics \& Adolescent Medicine, 161(12), 1154. doi:10.1001/archpedi.161.12.1154

Shin, E., Johnson, T. P., \& Rao, K. (2012). Survey mode effects on data quality: Comparison of Web and mail modes in a U.S. national panel survey. Social Science Computer Review, 30(2), 212-228. doi:10.1177/0894439311404508

Shock, N. W., Greulich, R. C., Andres, R., Arenberg, D., Costa, P. T., JR., Lakatta, E. G., \& Tobin, J. D. (1984). Normal human aging: The Baltimore longitudinal study of aging. Bethesda, MD: National Institutes of Health.

Sim, J., \& Wright, C. (2000). Research in health care: Concepts, designs and methods. Cheltenham Glos.: Stanley Thornes.

Singer, E., \& Kulka, R. A. (2002). Paying respondents for survey participation. In M. ver Ploeg, R. A. Moffitt, \& C. F. Citro (Eds.), Studies of welfare populations. Data collection and research issues. Washington, DC: National Academy.

Singer, E., van Hoewyk, J., \& Maher, M. P. (1998). Does the payment of incentives create expectation effects? Public Opinion Quarterly, 62(2), 152-164.

Sowislo, J. F., \& Orth, U. (2013). Does low self-esteem predict depression and anxiety? A meta-analysis of longitudinal studies. Psychological Bulletin, 139(1), 213-240. doi:10.1037/a0028931

Sparbel, K. J., \& Anderson, M. A. (2000). A continuity of care integrated literature review, part 2: Methodological issues. Journal of Nursing Scholarship, 32(2), 131-135. doi:10.1111/j.1547-5069.2000.00131.x

Sparks, G. G. (1995a). A final reply to Potter, Cooper, and Dupagne. Communication Theory, 5(3), 286-289. doi:10.1111/j.1468-2885.1995.tb00111.x

Sparks, G. G. (1995b). Comments concerning the claim that mass media research is "Prescientific": A response to Potter, Cooper, and Dupagne. Communication Theory, 5(3), 273-280. doi:10.1111/j.1468-2885.1995.tb00109.x

Statistik Austria. (2012). Bevölkerungszahl Österreichs stieg 2011 um rund 36.200 Personen [The Austrian population increased by about 36,200 people in 2011]. Wien. Available online: http://www.statistik.at/web_de/presse/061801

Statistisches Bundesamt. (2012). Alle politisch selbständigen Gemeinden mit ausgewählten Merkmalen am 30.06.2012. (2. Quartal 2012) [All politically independent communities including selected characteristics on 06/30/2012]. Available online: https:/www. destatis.de/DE/ZahlenFakten/LaenderRegionen/Regionales/Gemeindeverzeichnis/Administrativ/Archiv/GVAuszugQ/AuszugGV2QAktuell.html

Toepoel, V., Das, M., \& van Soest, A. (2009). Effects of design in Web surveys: Comparing trained and fresh respondents. Public Opinion Quarterly, 72(5), 985-1007. doi: 10.1093/poq/nfn060

Tufekci, Z., \& Wilson, C. (2012). Social media and the decision to participate in political protest: Observations from Tahrir Square. Journal of Communication, 62(2), 363-379. doi:10.1111/j.1460-2466.2012.01629.x

van Meter, K. M. (1990). Methodological and design issues: Techniques for assessing the representatives of snowball samples. In E. Y. Lambert (Ed.), NIDA Research Monograph: 
Vol. 98. The Collection and interpretation of data from hidden populations (pp. 31-42). Rockville, MD: National Institute on Drug Abuse. Available online: http://citeseerx.ist. psu.edu/viewdoc/download?doi=10.1.1.152.3744\&rep=rep1\&type=pdf\#page=38

Varedian, M., \& Forsman, G. (2003). Comparing propensity score weighting with other weighting methods: A case study. Presentation at the AAPOR 58th Annual Conference. Available online: http://www.websm.org/db/12/870/rec/

Vocino, A., \& Polonsky, M. J. (2011). Volunteering for research: A test of the psychometric properties of the volunteer functions inventory with online panellists. International Journal of Public Opinion Research, 23(4), 508-521.

Volkenandt, A. (2012). Worüber man sprechen sollte, worüber man spricht. Das subjektive Gefühl der Informiertheit unter besonderer Berücksichtigung interpersonaler Kommunikation über massenmediale Inhalte. [What one should talk about, what we talk about. The subjective feeling of being informed considering interpersonal communication about mass media contents]. Master thesis. Johannes Gutenberg-Universität, Mainz. Available online: http://www.avkomm.de/arbeitsproben/magisterarbeit

Wang, W., Rothschild, D., Goel, S., \& Gelman, A. (2015). Forecasting elections with nonrepresentative polls. International Journal of Forecasting, 31(3), 980-991. doi:10.1016/ j.ijforecast.2014.06.001

Weimann, G. (1982). On the importance of marginality: One more step into the two-step flow of communication. American Sociological Review, 47(6), 764-773. doi:10.2307/ 2095212

Whitehead, L. C. (2007). Methodological and ethical issues in Internet-mediated research in the field of health: An integrated review of the literature. Social Science \& Medicine, 65(4), 782-791. doi:10.1016/j.socscimed.2007.03.005

Winer, R. S. (1983). Attrition bias in econometric models estimated with panel data. Journal of Marketing Research, 20(2), 177-186.

Zagorsky, J. L., \& Rhoton, P. (2008). The effects of promised monetary incentives on attrition in a long-term panel survey. Public Opinion Quarterly, 72(3), 502-513.

Zimbardo, P. G. (2007). The Lucifer effect: Understanding how good people turn evil. New York: Random House. 